\title{
Helical Nanographenes Embedded with Contiguous Azulene Units
}

\section{$\operatorname{AUTHOR}(\mathrm{S})$ :}

Ogawa, Naoki; Yamaoka, Yousuke; Takikawa, Hiroshi; Yamada, Ken-ichi; Takasu, Kiyosei

\section{CITATION:}

Ogawa, Naoki ...[et al]. Helical Nanographenes Embedded with Contiguous Azulene Units. Journal of the American Chemical Society 2020, 142(31): 13322-13327

\section{ISSUE DATE:}

2020-08-05

URL:

http://hdl.handle.net/2433/255251

\section{RIGHT:}

This document is the Accepted Manuscript version of a Published Work that appeared in final form in Journal of the American Chemical Society, copyright $\odot$ American Chemical Society after peer review and technical editing by the publisher. To access the final edited and published work see https://doi.org/10.1021/jacs.0c06156.; The full-text file will be made open to the public on 17 July 2021 in accordance with publisher's 'Terms and Conditions for Self-Archiving': この論文は出版社版でありません。引用の際には出版社版をご確認ご利用ください。; This is not the published version. Please cite only the published version. 


\title{
Helical Nanographenes Embedded with Contiguous Azulene Units
}

\author{
Naoki Ogawa, Yousuke Yamaoka, Hiroshi Takikawa, Ken-ichi Yamada, ${ }^{\dagger}$ and Kiyosei Takasu* \\ Graduate School of Pharmaceutical Sciences, Kyoto University, Yoshida, Sakyo-ku, Kyoto 606-8501, Japan
}

\section{Supporting Information Placeholder}

\begin{abstract}
The azulene moiety, composed of contiguous pentagonal and heptagonal rings, is a structural defect that alters the electronic, magnetic, and structural properties of graphenes and graphene nanoribbons. However, nanographenes embedded with an azulene cluster have not been widely investigated because these compounds are difficult to synthesize in their pure form. Herein, azulene-embedded nanographenes bearing a unique cove-type edge were synthesized by a novel synthetic protocol. Experimental and theoretical investigations revealed that this cove edge imparts stable helical chirality, unlike normal cove edges. The in-solution self-association behavior and the structural, electronic, and electrochemical properties were also described in detail.
\end{abstract}

The topology of $\pi$-electrons is one of the most crucial factors determining the properties of nanographenes. Accordingly, considerable efforts have been devoted toward synthesizing and elucidating the properties of topologically diverse nanographenes, whose hexagonal rings are fused in different patterns. ${ }^{1-4}$ Researchers have also been interested in introducing non-hexagonal rings, such as pentagons, ${ }^{5-7}$ heptagons, ${ }^{8-10}$ or octagons, ${ }^{6,11}$ to achieve unique optical, electronic, and structural properties, distinct from those of $\pi$ systems composed of only hexagonal units.

Among the non-hexagonal ring systems, the azulene structure, composed of contiguous pentagonal and heptagonal rings, has been attracting considerable attention because of its interesting properties distinct from those of typical benzenoids. ${ }^{12}$ In particular, the azulene unit observed in graphenes as one of the structural defects breaks the structural symmetry to alter mechanical, magnetic, and electronic properties, as well as to open the non-zero band gap. ${ }^{13-}$ ${ }^{16}$ It is noteworthy that the azulene units in a single graphene molecule do not exist separately, but tend to accumulate to form clusters. ${ }^{16}$ In graphene nanoribbons (GNRs), whose edge structures determine their properties, the incorporation of azulene units results in unique edge structures. For example, a "narrowed" variant of the cove edge ${ }^{17-21}$ (Figure 1b) can be considered, wherein the "cove" comprises a contiguous 6-7-7-6 ring system instead of the four hexagonal rings of a normal cove edge (Figure 1a). a

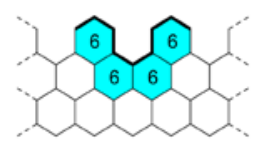

"Normal" Cove Edge

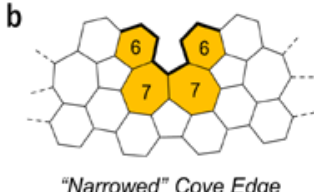

"Narrowed" Cove Edge
Figure 1. Structures of (a) "normal" cove edge and (b) its "narrowed" variant.

Although considerable efforts have been devoted to theoretically elucidate the nature of azulene-embedded graphenes and GNRs, ${ }^{13-}$

16 detailed experimental investigations are still limited, probably because preparation of such graphenes in a structurally uniform manner is not a straightforward process owing to the isomerization among 5-, 6-, and 7-membered rings. ${ }^{22,23}$ The bottom-up chemical synthesis of nanocarbons bearing model structures of such graphenes can resolve this problem. ${ }^{24-26}$ However, the bottom-up synthesis of nanocarbons with multiple azulene units is still limited because of the absence of reliable methods, unlike that of other nanocarbons composed only of hexagonal rings and isolated nonhexagonal ring(s). ${ }^{27-30}$ Peña, Pascual and co-workers ${ }^{31}$ and Müllen, Fasel, Feng and co-workers ${ }^{32,33}$ addressed this issue by conducting on-surface dehydrocyclization of rationally designed precursors to incorporate azulene units into nanocarbons. Mastalerz, ${ }^{34}$ Zhang, ${ }^{35}$ and $\mathrm{Chi}^{36}$ also achieved in-solution construction of highly fused azulene units via Scholl cyclization of ingeniously tailored precursors. Recently, Konishi and co-workers reported the preparation of azulene-embedded antiaromatic compounds by utilizing their aromatic dications as key intermediates. ${ }^{37}$ Despite these pioneering works, appropriate methods for synthesizing highly condensed, contiguous azulene structures, which appear in graphenes, have hardly been investigated. ${ }^{21}$

Herein, we report a bottom-up chemical synthesis and properties of azulene-embedded nanographenes (1; Figure 2). Their contiguous azulene structures condensed at the heptagonal rings were designed as a model structure representing one of the contiguous azulene units observed in graphenes. Compound $\mathbf{1}$ also has a helical structure that is identical to the basic structure of the narrowed variants of the cove edge. A newly developed photo-induced oxidative cyclization of fluoranthene 2 to construct an azulene structure enables us to obtain the key intermediate $\mathbf{3}$, leading to the successful generation of contiguous azulene units via further $\pi$-extension. 


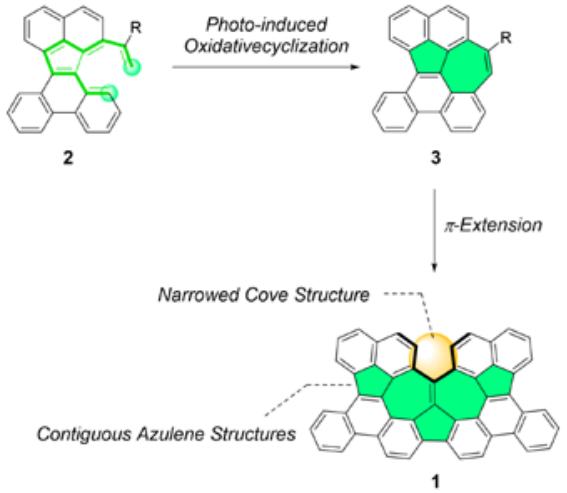

Figure 2. Structural design of and synthetic strategy toward nanographene 1.

In our previous report on PAHs, ${ }^{38}$ we reasoned that constructing an additional heptagon unit next to the pentagon of dibenzofluoranthene 2 would be a straightforward approach to obtaining a condensed azulene structure (3), because the pentagonal ring is surrounded by multiple benzene rings (Figure 2). Unfortunately, it was found that conventional $\pi$-extension reactions, such as intramolecular Friedel-Crafts acylation and Scholl cyclization, are not suitable for this purpose. ${ }^{39}$ After further investigation, it was established that 2 c consisting of an $\alpha$-styryl moiety is a suitable precursor to generate the desired azulene unit. Thus, activation of $\mathbf{2 c}$ by visiblelight irradiation $(475 \mathrm{~nm})$ in the presence of an oxidant resulted in a clean conversion to 3c via oxidative cyclization (Scheme 1, Eq. 1). Both irradiation and DDQ were necessary for this reaction, as irradiation without DDQ and irradiation-free DDQ treatment lead to the decomposition and recovery of $\mathbf{2 c}$, respectively. The utilization of visible light positively affects reaction efficiency; UV-light irradiation (low-pressure mercury-vapor lamp ${ }^{40}$ and heating to $250{ }^{\circ} \mathrm{C}$ caused low yields (52\% and $40 \%$, respectively). Based on these control experiments as well as theoretical calculations, it can be considered that ring-closure proceeds via photo-induced $10 \pi$ electrocyclization, ${ }^{41-43,39}$ although the possibility of radical mechanism cannot be entirely dismissed. ${ }^{39}$ The synthetic utility of this novel method was highlighted by its application for the synthesis of boronate ester 3a (Scheme 1, Eq. 2), as the C-B bond on its heptagonal ring would promote further $\pi$-extension via transitionmetal-catalyzed cross-coupling reactions. ${ }^{44}$

Scheme 1. Conversion of dibenzofluoranthene 2 to azulene 3 via visible-light-promoted oxidative cyclization.
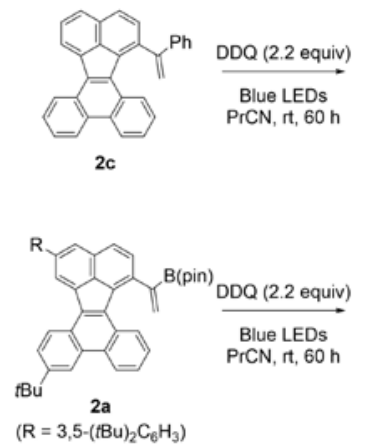
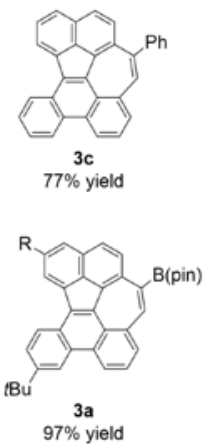

(1)

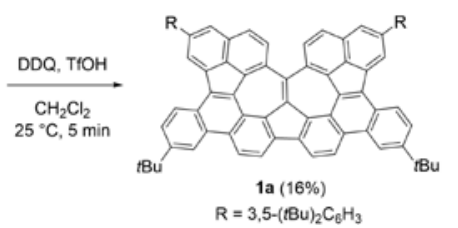

The structural properties of 1a were investigated by X-ray crystallography (Figure 3). ${ }^{45}$ The azulene structures in 1a showed significant bond length alternation, varying between $1.39 \AA$ and 1.49 $\AA$, as observed in unsubstituted azulene (Figure $3 b){ }^{46}$ The edge shown as the bottom side in the figure is planar, and 1a was stacked together on that side (Figures 3c and 3d). In contrast, the cove region has a significantly distorted helical structure, and the angle of the eclipsed rings (shown as B and B' in Figure 3a) is $46.9^{\circ}$, larger than that of the normal cove edge $\left(38^{\circ}\right) .{ }^{17}$ The enantiomers arising from this cove region were alternatively arranged with a distance as short as $3.3 \AA$, suggesting strong intermolecular $\pi-\pi$ stacking interactions (Figure 3c and 3d). Furthermore, the in-solution selfassociation behavior is attributed to the strong intermolecular interactions among planar regions: the ${ }^{1} \mathrm{H}$ NMR spectra of 1 a showed significant concentration dependence, i.e., the peaks of protons located at the phenanthrene moiety shifted upfield as the concentration increased. These upfield-shifts resulted from face-to-face aggregations, ${ }^{47}$ and the association constant $\left(K_{2}\right)$ in $\mathrm{CDCl}_{3} / \mathrm{CS}_{2}(1: 1)$ was estimated to be $74.1 \pm 25.5 \mathrm{M}^{-1} .39,48$ 


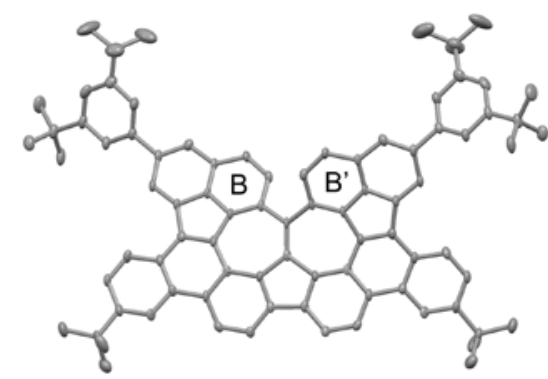

C

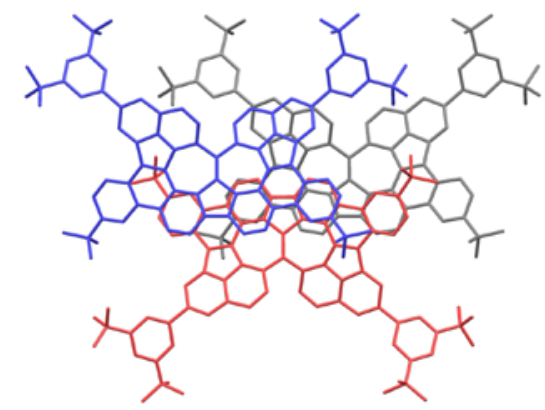

b

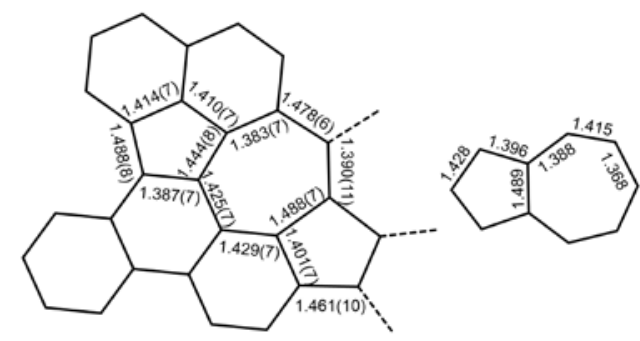

d

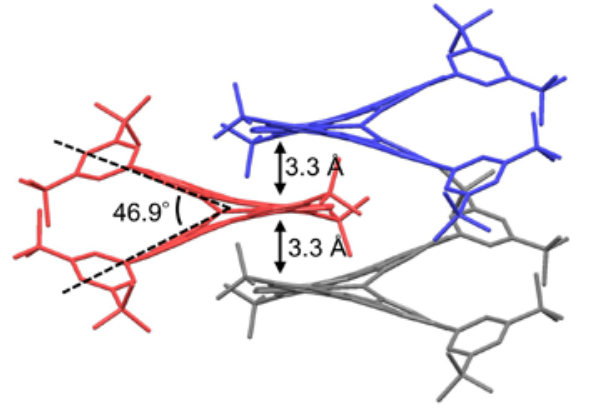

Figure 3. Crystal structure of 1a. Hydrogen atoms are omitted for clarity. (a) Top view (thermal ellipsoids are shown at 50\% probability). (b) Bond length of 1a (left) and azulene (right). (c) Top and (d) side views of the packing structure.

To elucidate the nature of narrowed-cove structure of 1 comprising a contiguous 6-7-7-6 ring system, we focused on its racemization barrier. The enantiomers of $\mathbf{1 b}$ could be separated by chiral HPLC, and the two separated fractions showed clear mirror-symmetric CD spectra (Figure 4a). The stable helicity of the 6-7-7-6 rings is in clear contrast to that of the normal cove structure comprising a [4] helicene structure, which racemizes immediately. ${ }^{17,49}$ Theoretical calculations revealed a high racemization barrier of the model structure (1c; $\Delta G^{\ddagger}$ calc $\left.=29.2 \mathrm{kcal} / \mathrm{mol}\right)$, which lies between those of [5] helicene and [6] helicene (Figures $4 \mathrm{~b}$ and $4 \mathrm{c}$ ). ${ }^{50}$ This theoretically estimated racemization barrier is in good agreement with the experimentally estimated one $\left(\Delta H^{\ddagger}=29.6 \mathrm{kcal} / \mathrm{mol}\right)$, supporting the calculated racemization mechanism. ${ }^{39}$ The achievement of this high racemization barrier is attributed to the presence of a highly distorted transition state necessitated by the large interior angle of the 7-membered ring.

The nucleus-independent chemical shifts (NICS) were calculated to gain insight into the local aromaticity of each ring (Figure 5). According to the calculations, all hexagonal rings showed negative NICS(1) values, confirming their aromatic character. In detail, the naphthalene-like A-B ring system showed higher NICS(1) values than naphthalene ${ }^{51}(-10.7 \mathrm{ppm})$, suggesting the weaker local aromaticity of these rings. Similarly, the phenanthrene-like E-F-G ring system showed higher NICS(1) values than the unsubstituted phenanthrene. ${ }^{51}$ The weaker local aromaticity of these hexagonal rings can be attributed to the $\pi$-conjugations between the A-B and $\mathrm{E}-\mathrm{F}-\mathrm{G}$ ring systems in the embedded azulene structures. The pentagonal rings $(\mathrm{C}$ and $\mathrm{H})$ and the heptagonal ring $(\mathrm{D})$ showed negative NICS(1) values (-17.8 ppm and -7.82 for pentagonal and heptagonal rings, respectively), indicating that these rings have significantly weaker aromaticity than unsubstituted azulene ${ }^{51}$, presumably due to the fused benzene rings (A, B, F, and G).

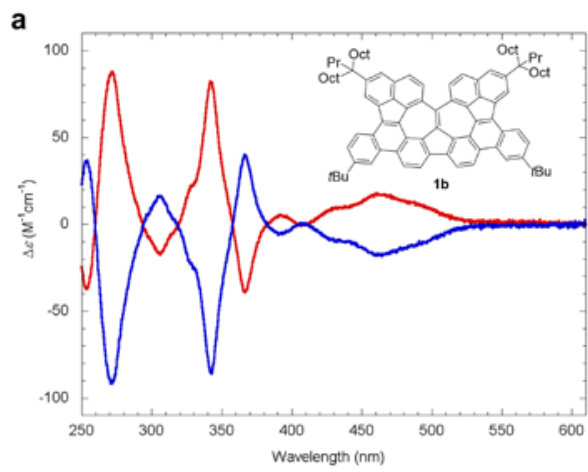

b

Figure 4. (a) CD spectra of $\mathbf{1 b}\left(1.0 \times 10^{-4} \mathrm{M}\right.$ in hexane). (b) Computed racemization process of the model compound, 1c. Relative Gibbs free energies (kcal/mol) are given in parentheses. (c) Comparison of the racemization barriers among 1c and helicenes. Racemization barriers $(\mathrm{kcal} / \mathrm{mol})$ are shown in parentheses. 


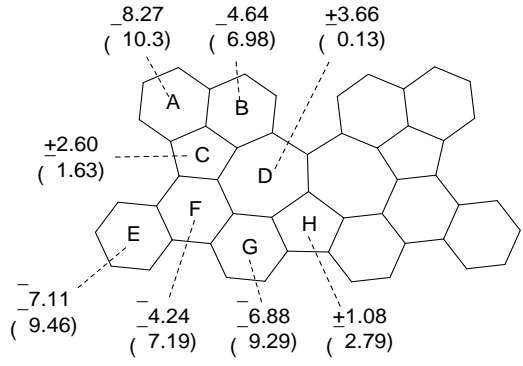

Figure 5. NICS(0) and NICS(1) values of 1c. NICS(1) values are given in parentheses.

The UV-vis absorption spectra showed two weak bands at 660 and $600 \mathrm{~nm}$ and two strong bands at 477 and $404 \mathrm{~nm}$ in the visible region (Figure. 6a). According to the TD-DFT calculations, the weak bands at 660 and $600 \mathrm{~nm}$ could be assigned to HOMO $\rightarrow$ LUMO $\left(\lambda_{\text {calc }}=635 \mathrm{~nm}, f=0.062\right)$ and HOMO-1 $\rightarrow$ LUMO transitions $\left(\lambda_{\text {calc }}=584, f=0.036\right)$, respectively (Figure. $\left.6 \mathrm{~b}\right)$. The strong band at $477 \mathrm{~nm}$ was assigned to the $\mathrm{HOMO} \rightarrow \mathrm{LUMO}+1\left(\lambda_{\text {calc }}=\right.$ $548, f=0.247)$ and HOMO-2 $\rightarrow$ LUMO $\left(\lambda_{\text {calc }}=513, f=0.421\right)$ transitions. The HOMO is largely distributed over the E-G-F and C-D rings, and the local shapes are similar to those of unsubstituted phenanthrene and azulene, while the energy level is higher (1a, $-5.36 \mathrm{eV}$; phenanthrene, $-6.18 \mathrm{eV}$; azulene, $-5.67 \mathrm{eV}){ }^{39}$ The LUMO distribution shows dibenzofulvene-like character on the $\mathrm{G}-$ $\mathrm{H}-\mathrm{G}$ ' rings and exocyclic double bond of $\mathrm{H}$ ring and affirms the azulene-like character on the $\mathrm{C}-\mathrm{D}$ ring system, with a lower energy level $(-2.88 \mathrm{eV})$ than those of dibenzofulvene $(-2.04 \mathrm{eV})$ and azulene $(-2.36 \mathrm{eV}){ }^{39}$

a

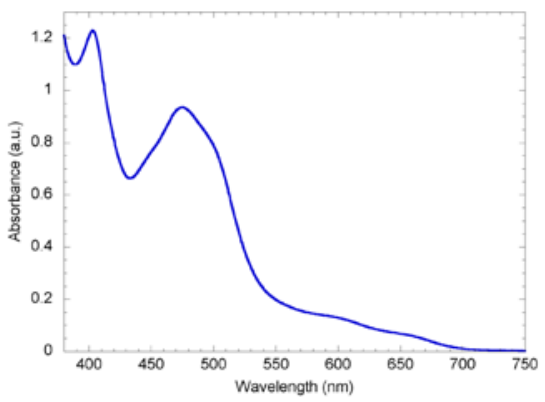

b
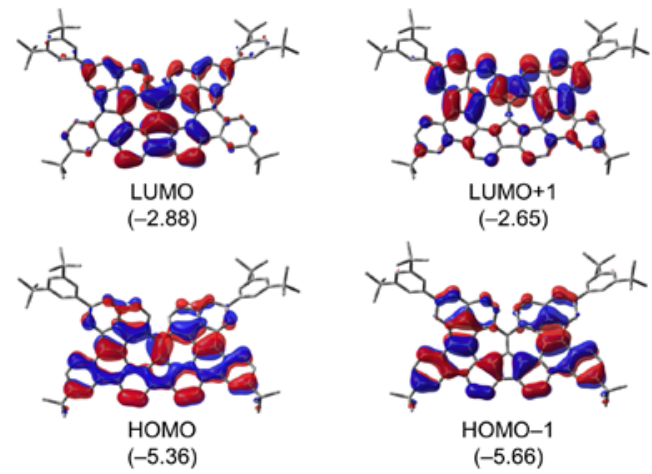

Figure 6. (a) Experimental UV-vis absorption spectra $\left(1.0 \times 10^{-4} \mathrm{M}\right.$ in $\mathrm{CH}_{2} \mathrm{Cl}_{2}$ ) and (b) molecular orbitals of $\mathbf{1 a}$.
The CV analysis confirms that $\mathbf{1 b}$ is stable over both electrochemical oxidation and reduction; it shows three oxidation peaks at $0.47,0.69$, and $1.0 \mathrm{~V}$ and one reduction peak at $-1.5 \mathrm{~V}\left(\mathrm{vs}\right.$. $\left.\mathrm{Ag} / \mathrm{Ag}^{+}\right)$ (Figure 7a). In CV and DPV voltammograms, the first oxidation peak was split into two small peaks (P1 and P2). Variable-concentration DPV analysis (Figure 7b) suggested that this splitting of the oxidation peaks resulted from the self-association characteristic of $\mathbf{1 b}$; as P1 weakened with decreasing concentration, whereas P2 strengthened, P1 and P2 can be assigned as the oxidation peaks of aggregated and monomeric species, respectively.
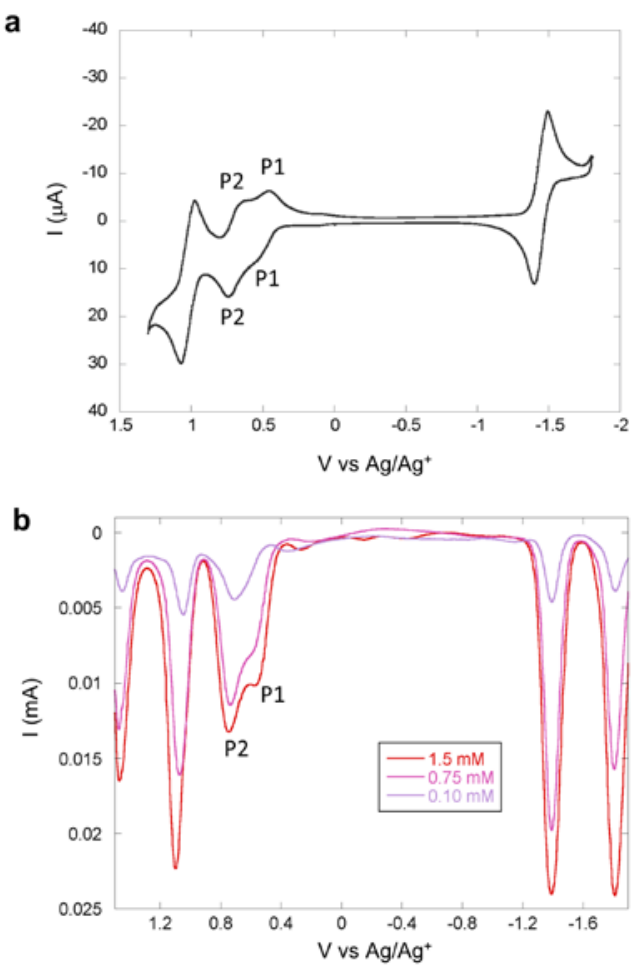

Figure 7. (a) $\mathrm{CV}$ voltammogram of $\mathbf{1 b}\left(2.0 \times 10^{-3} \mathrm{M}\right.$ in $\left.\mathrm{CH}_{2} \mathrm{Cl}_{2}\right)$. (b) Variable-concentration DPV voltammogram of $\mathbf{1 b}$ in $\mathrm{CH}_{2} \mathrm{Cl}_{2}$.

In summary, a novel method for the construction of a highly condensed azulene unit has been developed to synthesize nanographene 1, featuring embedded contiguous azulene units and a narrowed cove-type edge. Experimental and theoretical results indicated that the cove-type region imparted stable chirality, in contrast to normal cove edges. The X-ray diffraction analysis, variable-concentration NMR, and DPV revealed the tendency of $\mathbf{1}$ to stack via $\pi-\pi$ interactions both in the crystal form and in solution.

\section{ASSOCIATED CONTENT}

\section{Supporting Information}

The Supporting Information is available free of charge on the ACS Publications website at DOI:

Supplementary figures, experimental procedures, characterization data, ${ }^{1} \mathrm{H}$ and ${ }^{13} \mathrm{C}$ NMR spectra (PDF)

\section{AUTHOR INFORMATION}

\section{Corresponding Author}

*E-mail: kay-t@pharm.kyoto-u.ac.jp. 


\section{ORCID}

Naoki Ogawa: 0000-0002-1120-7467

Yousuke Yamaoka: 0000-0003-3641-8823

Hiroshi Takikawa: 0000-0002-4414-2129

Kiyosei Takasu: 0000-0002-1798-7919

\section{Present Addresses}

${ }^{\dagger}$ Graduate School of Pharmaceutical Sciences, Tokushima University, Shomachi, Tokushima 770-8505, Japan (K.Y.).

\section{Notes}

The authors declare no competing financial interests.

\section{ACKNOWLEDGMENT}

We acknowledge financial support by JSPS KAKENHI to K.T. (Grant Nos. JP19K22185, JP19H03350, and JP18H04406), JSPS for a research fellowship for young scientists to N.O. (JP19J14061), a Platform for Drug Design, Discovery and Development grant from MEXT to K.T., and the Sasakawa Scientific Research Grant from The Japan Science Society to N.O. We thank Prof. Takashi Kubo (Graduate School of Science, Osaka University) for electrochemical analyses, and Dr. Hiroyasu Sato (Rigaku Corporation) for $\mathrm{X}$-ray crystallography. We used the supercomputer of ACCMS, Kyoto University.

\section{REFERENCES}

(1) Chen, Q.; Schollmeyer, D.; Müllen, K.; Narita, A. Synthesis of Circumpyrene by Alkyne Benzannulation of Brominated Dibenzo[hi, st]Ovalene. J. Am. Chem. Soc. 2019, 141, 19994-19999.

(2) Yao, X.; Wang, X. Y.; Simpson, C.; Paternò, G. M.; Guizzardi, M.; Wagner, M.; Cerullo, G.; Scotognella, F.; Watson, M. D.; Narita, A.; Müllen, K. Regioselective Hydrogenation of a 60-Carbon Nanographene Molecule toward a Circumbiphenyl Core. J. Am. Chem. Soc. 2019, 141, 4230-4234.

(3) Zeng, W.; Gopalakrishna, T. Y.; Phan, H.; Tanaka, T.; Herng, T. S.; Ding, J.; Osuka, A.; Wu, J. Superoctazethrene: An Open-Shell Graphenelike Molecule Possessing Large Diradical Character but Still with Reasonable Stability. J. Am. Chem. Soc. 2018, 140, 14054-14058.

(4) Ajayakumar, M. R.; Fu, Y.; Ma, J.; Hennersdorf, F.; Komber, H.; Weigand, J. J.; Alfonsov, A.; Popov, A. A.; Berger, R.; Liu, J.; Müllen, K.; Feng, X. Toward Full Zigzag-Edged Nanographenes: Peri-Tetracene and Its Corresponding Circumanthracene. J. Am. Chem. Soc. 2018, 140, 62406244.

(5) Zhu, Z.-Z.; Chen, Z.-C.; Yao, Y.-R.; Cui, C.-H.; Li, S.-H.; Zhao, X.-J.; Zhang, Q.; Tian, H.-R.; Xu, P.-Y.; Xie, F.-F.; Xie, X.-M.; Tan, Y.-Z.; Deng, S.-L.; Quimby, J. M.; Scott, L. T.; Xie, S.-Y.; Huang, R.-B.; Zheng, L.-S. Rational synthesis of an atomically precise carboncone under mild conditions. Sci. Adv. 2019, 5, eaaw0982.

(6) Kirschbaum, T.; Rominger, F.; Mastalerz, M. A Chiral Polycyclic Aromatic Hydrocarbon Monkey Saddle. Angew. Chem., Int. Ed. 2020, 59, 270-274.

(7) Liu, J.; Narita, A.; Osella, S.; Zhang, W.; Schollmeyer, D.; Beljonne, D.; Feng, X.; Müllen, K. Unexpected Scholl Reaction of 6,7,13,14Tetraarylbenzo[k]Tetraphene: Selective Formation of Five-Membered Rings in Polycyclic Aromatic Hydrocarbons. J. Am. Chem. Soc. 2016, 138, 2602-2608.

(8) Cruz, C. M.; Márquez, I. R.; Mariz, I. F. A.; Blanco, V.; SánchezSánchez, C.; Sobrado, J. M.; Martín-Gago, J. A.; Cuerva, J. M.; Maçôas, E.; Campaña, A. G. Enantiopure Distorted Ribbon-Shaped Nanographene Combining Two-Photon Absorption-Based Upconversion and Circularly Polarized Luminescence. Chem. Sci. 2018, 9, 3917-3924.

(9) Márquez, I. R.; Fuentes, N.; Cruz, C. M.; Puente-Muñoz, V.; Sotorrios, L.; Marcos, M. L.; Choquesillo-Lazarte, D.; Biel, B.; Crovetto, L.; GómezBengoa, E.; Gonzólez, T.; Martin, R.; Cuerva, J. M.; Campaña, A. G.
Versatile Synthesis and Enlargement of Functionalized Distorted Heptagon-Containing Nanographenes. Chem. Sci. 2017, 8, 1068-1074. (10) Kawasumi, K.; Zhang, Q.; Segawa, Y.; Scott, L. T.; Itami, K. A Grossly Warped Nanographene and the Consequences of Multiple OddMembered-Ring Defects. Nat. Chem. 2013, 5, 739-744.

(11) Pun, S. H.; Wang, Y.; Chu, M.; Chan, C. K.; Li, Y.; Liu, Z.; Miao, Q. Synthesis, Structures, and Properties of Heptabenzo[7]Circulene and Octabenzo[8]Circulene. J. Am. Chem. Soc. 2019, 141, 9680-9686.

(12) Michl, J.; Thulstrup, E. W. Why Is Azulene Blue and Anthracene White? A Simple Mo Picture. Tetrahedron 1976, 32, 205-209.

(13) Yazyev, O. V.; Louie, S. G. Topological Defects in Graphene: Dislocations and Grain Boundaries. Phys. Rev. B 2010, 81.

(14) Vicarelli, L.; Heerema, S. J.; Dekker, C.; Zandbergen, H. W. Controlling Defects in Graphene for Optimizing the Electrical Properties of Graphene Nanodevices. ACS Nano 2015, 9, 3428-3435.

(15) Banhart, F.; Kotakoski, J.; Krasheninnikov, A. V. Structural Defects in Graphene. ACS Nano 2011, 5, 26-41.

(16) Lu, J.; Bao, Y.; Su, C. L.; Loh, K. P. Properties of Strained Structures and Topological Defects in Graphene. ACS Nano 2013, 7, 8350-8357.

(17) Liu, J.; Li, B. W.; Tan, Y. Z.; Giannakopoulos, A.; Sanchez-Sanchez, C.; Beljonne, D.; Ruffieux, P.; Fasel, R.; Feng, X.; Müllen, K. Toward Cove-Edged Low Band Gap Graphene Nanoribbons. J. Am. Chem. Soc. 2015, 137, 6097-6103.

(18) Nagarajan, K.; Mallia, A. R.; Muraleedharan, K.; Hariharan, M. Enhanced Intersystem Crossing in Core-Twisted Aromatics. Chem. Sci. 2017, 8, 1776-1782.

(19) Sisto, T. J.; Zhong, Y.; Zhang, B.; Trinh, M. T.; Miyata, K.; Zhong, X.; Zhu, X. Y.; Steigerwald, M. L.; Ng, F.; Nuckolls, C. Long, Atomically Precise Donor-Acceptor Cove-Edge Nanoribbons as Electron Acceptors. $J$. Am. Chem. Soc. 2017, 139, 5648-5651.

(20) Yano, Y.; Wang, F.; Mitoma, N.; Miyauchi, Y.; Ito, H.; Itami, K. StepGrowth Annulative $\pi$-Extension Polymerization for Synthesis of CoveType Graphene Nanoribbons. J. Am. Chem. Soc. 2020, 142, 1686-1691.

(21) Gu, Y.; Muñoz-Mármol, R.; Wu, S.; Han, Y.; Ni, Y.; Díaz-García, M. A.; Casado, J; Wu, J. Cove-Edged Nanographenes with Localized Double Bonds. Angew. Chem., Int. Ed. 2020, 132, 8190-8194.

(22) Fan, Q.; Jimenez, D. M.; Ebeling, D.; Krug, C. K.; Brechmann, L.; Hilt, G.; Hieringer, W.; Schirmeisen, A.; Gottfried, J. M. Nanoribbons with Non-Alternant Topology from Fusion of Polyazulene: Carbon Allotropes Beyond Graphene. J. Am. Chem. Soc. 2019, 141, 17713-17720. (23) Wang, Y.; Page, A. J.; Nishimoto, Y.; Qian, H. J.; Morokuma, K.; Irle, S. Template Effect in the Competition between Haeckelite and Graphene Growth on Ni(111): Quantum Chemical Molecular Dynamics Simulations. J. Am. Chem. Soc. 2011, 133, 18837-18842.

(24) Narita, A.; Wang, X. Y.; Feng, X.; Müllen, K. New Advances in Nanographene Chemistry. Chem. Soc. Rev. 2015, 44, 6616-6643.

(25) Segawa, Y.; Ito, H.; Itami, K. Structurally Uniform and Atomically Precise Carbon Nanostructures. Nat. Rev. Mater. 2016, 1, 15002.

(26) Yano, Y.; Mitoma, N.; Ito, H.; Itami, K. A Quest for Structurally Uniform Graphene Nanoribbons: Synthesis, Properties, and Applications. $J$. Org. Chem. 2020, 85, 4-33.

(27) Ma, J.; Fu, Y.; Dmitrieva, E.; Liu, F.; Komber, H.; Hennersdorf, F.; Popov, A. A.; Weigand, J. J.; Liu, J.; Feng, X. Helical Nanographenes Containing an Azulene Unit: Synthesis, Crystal Structures, and Properties. Angew. Chem., Int. Ed. 2020, 59, 5637-5642.

(28) Ziegler, K.; Hafner, K. Eine Rationelle Synthese Des Azulens. Angew. Chem. 1955, 67, 301-301.

(29) Lellek, V.; Hansen, H. J. Surprising Formation of Highly Substituted Azulenes on Thermolysis of 4,5,6,7,8-Pentamethyl-2hEyelohepta[b]Furan-2-One and Heptalene Formation with the New Azulenes. Helv. Chim. Acta 2001, 84, 1712-1736.

(30) Carret, S.; Blanc, A.; Coquerel, Y.; Berthod, M.; Greene, A. E.; Deprés, J. P. Approach to the Blues: A Highly Flexible Route to the Azulenes. Angew. Chem., Int. Ed. 2005, 44, 5130-5133.

(31) Hieulle, J.; Carbonell-Sanromà, E.; Vilas-Varela, M.; Garcia-Lekue, A.; Guitián, E.; Peña, D.; Pascual, J. I. On-Surface Route for Producing Planar Nanographenes with Azulene Moieties. Nano Lett. 2018, 18, 418423.

(32) Liu, J.; Mishra, S.; Pignedoli, C. A.; Passerone, D.; Urgel, J. I.; Fabrizio, A.; Lohr, T. G.; Ma, J.; Komber, H.; Baumgarten, M.; Corminboeuf, C.; 
Berger, R.; Ruffieux, P.; Müllen, K.; Fasel, R.; Feng, X. Open-Shell Nonbenzenoid Nanographenes Containing Two Pairs of Pentagonal and Heptagonal Rings. J. Am. Chem. Soc. 2019, 141, 12011-12020.

(33) Mishra, S.; Lohr, T. G.; Pignedoli, C. A.; Liu, J.; Berger, R.; Urgel, J. I.; Müllen, K.; Feng, X.; Ruffieux, P.; Fasel, R. Tailoring Bond Topologies in Open-Shell Graphene Nanostructures. ACS Nano 2018, 12, 11917-11927. (34) Mastalerz, M.; Yang, X.; Rominger, F. Contorted Polycyclic Aromatic Hydrocarbons with Two Embedded Azulene Units. Angew. Chem., Int. Ed. 2019, 58, 17577-17582.

(35) Zhang, X.; Huang, Y.; Zhang, J.; Meng, W.; Peng, Q.; Kong, R.; Xiao, Z.; Liu, J.; Huang, M.; Yi, Y.; Chen, L.; Fan, Q.; Lin, G.; Liu, Z.; Zhang, G.; Jiang, L.; Zhang, D. Organic Semiconductors Dicyclohepta [ijkl,uvwx] Rubicene with Two Pentagons and Two Heptagons as a Stable and Planar Non-Benzenoid Nanographene. Angew. Chem. Int. Ed. 2019, 59, 35293533.

(36) Han, Y.; Xue, Z.; Li, G.; Gu, Y.; Ni, Y.; Dong, S.; Chi, C. Formation of Azulene-Embedded Nanographene: Naphthalene to Azulene Rearrangement During the Scholl Reaction. Angew. Chem., Int. Ed. 2020, 132, 9111-9116.

(37) Konishi, A.; Horii, K.; Shiomi, D.; Sato, K.; Takui, T.; Yasuda, M. Open-Shell and Antiaromatic Character Induced by the Highly Symmetric Geometry of the Planar Heptalene Structure: Synthesis and Characterization of a Nonalternant Isomer of Bisanthene. J. Am. Chem. Soc. 2019, 141, 10165-10170.

(38) Ogawa, N.; Yamaoka, Y.; Yamada, K. I.; Takasu, K. Synthesis of $\pi$ Extended Fluoranthenes via a KHMDS-Promoted Anionic-Radical Reaction Cascade. Org. Lett. 2017, 19, 3327-3330.

(39) See the supporting information for details.

(40) Mallory, F. B.; Mallory, C. W. Photocyclization of stilbenes and related molecules. Org. React. 1984, 30, 1-449.

(41) Villedieu-Percheron, E.; Catak, S.; Zurwerra, D.; Staiger, R.; Lachia, M.; De Mesmaeker, A. $6 \pi / 10 \pi$-Electrocyclization of Ketene-Iminium Salts for the Synthesis of Substituted Naphthylamines. Tetrahedron Lett. 2014, $55,2446-2449$.

(42) Gobbi, L.; Seiler, P.; Diederich, F.; Kristallographie, L.; Zürich, C.-; Pasteur, Â. L.; No, U. M. R. Photoswitchable TetraethynyletheneDihydroazulene Chromophores. Helv. Chim. Acta 2001, 84, 743-777.

(43) Ziegler, K; Hafner, K. Eine rationelle Synthese des Azulens. Angew. Chem. 1955, 67, 301-301.

(44) Miyaura, N.; Suzuki, A. Palladium-Catalyzed Cross-Coupling Reactions of Organoboron Compounds. Chem. Rev. 1995, 95, 2457-2483.

(45) Sheldrick, G. M. A Short History of SHELX. Acta Crystallogr. Sect. A Found. Crystallogr. 2008, 64, 112-122.

(46) Dittrich, B.; Fabbiani, F. P. A.; Henn, J.; Schmidt, M. U.; Macchi, P.; Meindl, K.; Spackman, M. A. Azulene Revisited: Solid-State Structure, Invariom Modeling and Lattice-Energy Minimization of a Classical Example of Disorder. Acta Crystallogr. Sect. B Struct. Sci. Cryst. Eng. Mater. 2018, 74, 416-426.

(47) Nakamura, K.; Okubo, H.; Yamaguchi, M. Synthesis and SelfAggregation of Cyclic Alkynes Containing Helicene. Org. Lett. 2001, 3, 1097-1099.

(48) Tobe, Y.; Utsumi, N.; Kawabata, K.; Nagano, A.; Adachi, K.; Araki, S.; Sonoda, M.; Hirose, K.; Naemura, K. M-Diethynylbenzene Macrocycles: Syntheses and Self-Association Behavior in Solution. J. Am. Chem. Soc. 2002, 124, 5350-5364.

(49) Barroso, J.; Cabellos, J. L.; Pan, S.; Murillo, F.; Zarate, X.; FernandezHerrera, M. A.; Merino, G. Revisiting the Racemization Mechanism of Helicenes. Chem. Commun. 2017, 54, 188-191.

(50) Martin, R. H.; Marchant, M. J. Thermal Racemization of Hepta-, Octa-, and Nonahelicene. Kinetic Results, Reaction Path and Experimental Proofs That the Racemization of Hexa- and Heptahelicene Does Not Involve an Intramolecular Double Diels-Alder Reaction. Tetrahedron 1974, 30, 347349.

(51) Chen, Z.; Wannere, C. S.; Corminboeuf, C.; Puchta, R.; von Ragué Schleyer, P. Nucleus-Independent Chemical Shifts (NICS) as an Aromaticity Criterion. Chem. Rev. 2005, 105, 3842-3888. 
TOC graphic is shown below:

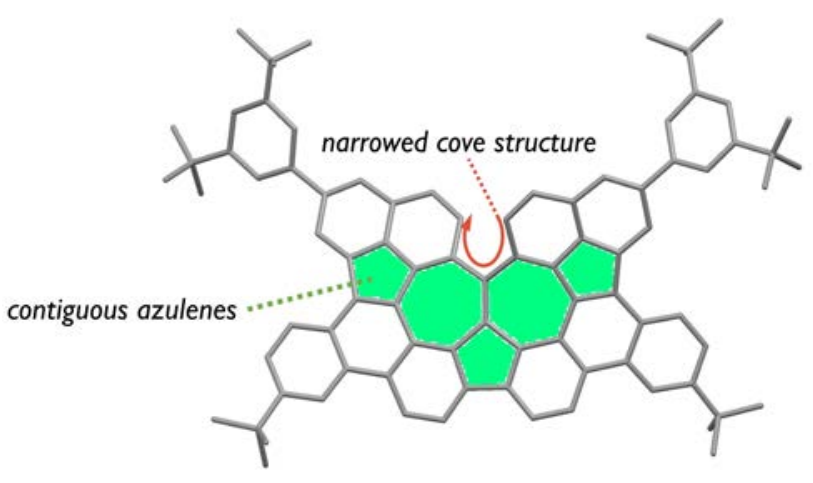

